\title{
Staples Versus Sutures For Skin Closure In Hip Arthroplasty: A Meta-Analysis And Systematic Review
}

\author{
Zirui Liu \\ The First Affiliated Hospital of Zhengzhou University \\ Binfeng Liu \\ The Second Xiangya Hospital, Central South University \\ Hao Yang \\ The First Affiliated Hospital of Zhengzhou University \\ Liang Zhao ( $\nabla$ zhao822003@163.om ) \\ The First Affiliated Hospital of Zhengzhou University
}

\section{Research article}

Keywords: Wound closure, Staples, Suture, Hip arthroplasty.

Posted Date: October 14th, 2021

DOI: https://doi.org/10.21203/rs.3.rs-958981/v1

License: (c) (i) This work is licensed under a Creative Commons Attribution 4.0 International License. Read Full License

Version of Record: A version of this preprint was published at Journal of Orthopaedic Surgery and Research on December 1st, 2021. See the published version at https://doi.org/10.1186/s13018-021-02870-z. 


\section{Abstract}

Objective: The purpose of this present study was to estimate complication and other outcomes associated with staples and sutures closure after hip arthroplasty through meta- analysis techniques and system review.

Methods: We searched for articles on EMBASE, PubMed, Medline, Web of Science and Cochrane Library. Eligibility of the searched trials. Cochrane Collaboration's Review Manager software is used to perform meta-analysis.

Results: Four randomized controlled trials and one retrospective cohort trial chosen into our study. Our study indicated that the risk of infection and prolonged discharge higher with staples than with sutures for skin closure after hip arthroplasty. Meanwhile, there was no significant difference in allergic reaction, dehiscence, inflammation, abscess formation, Hollander Wound Evaluation Score and patient's satisfaction with skin closure methods between the two groups after hip arthroplasty. However, the suture group may require additional operating time.

Conclusions: Closure with suture have a lower risk of infection and prolonged discharge when compared with staples skin closure in hip arthroplasty, while it may take more time.

\section{Introduction}

Hip arthroplasty is the famous surgical operation for the treatment of degenerative and traumatic hip disease. With the aging of population and the progress of medical technology,the rate of arthroplasty has consistently been rising over the past decades $(1,2)$. Hip arthroplasty included total hip arthroplasty and hemiarthroplasty(3). It is estimated that by 2030 , the major total hip arthroplasty operations in the United States will be 572,000 per year, an increase of $174 \%$ over 2005.(4).

Wound complications are one of the main morbidity of hip arthroplasty, which can prolong hospitalization time or lead to readmission, increase costs and reduce patient satisfaction $(5,6)$. Surgical site infections (SSIs) are one of the most common, and most important complication after hip arthroplasty(7). Good skin closure in hip arthroplasty can achieve an appropriate closure and rapid healing, with acceptable cosmesis and minimize complications such as infection, delayed dehiscence and hematoma(5); besides, the stress of early activities and accelerated rehabilitation programs on wounds highlights the importance of skin closure(8).

There are many kinds of skin closure methods in hip arthroplasty, staples and sutures are the two most commonly used skin closure materials in hip arthroplasty(9). However, there seems to be no consensus in the literature as to which method of skin closure is superior in hip arthroplasty. some study show that skin staples were associated with a similar complication rate to an sutures, at the same time, they report that suture can reduce costs and sutures are less painful to remove(6, 10-12). In addition, Yao Lu et al found that the incidence of complications of suture closure was significantly lower than that of suture staples(13). The main disadvantage of suture is that it takes longer time to suture the wound, besides suture also requires surgeons to have better suture skills(14). Unlike suture, the surface of the staples rarely touches the edge of the wound and does not penetrate the incision at the depth of the incision. Staplers do much less damage to wound defense and also reduce the immune response. In the process of suture and removal, staples are also considered faster than sutures $(15,16)$. However Singh, B.et al $(6)$ shows that using staples more than three times costlier than sutures. Therefore, further critical evidence is needed to prove which skin closure methods is more suitable for surgical suture after hip arthroplasty.

Until recently some meta-analyses and systematic reviews comparing staples with sutures for skin closure after orthopedic procedures or total knee arthroplasty have been published(17-20). However, after extensive searching for a large number of literature in the past, there was no related study comparing the wound complication, perioperative details and resource utilization of patients whose skin closure were closed with staples or sutures after hip arthroplasty. Meanwhile, some randomized controlled trials about staples versus sutures for wound closure in hip arthroplasty have been published in recent years. The purpose of this present study was to estimate complication and other outcomes associated with staples and sutures closure after hip arthroplasty through meta- analysis techniques and system review. We hypothesized that skin staples would be associated with better outcomes in the assessment of all relevant variables.

\section{Materials And Methods}

\section{Literature search}

From the establishment of the database to Mar 2021, two investigators independently conducted an extensive search of electronic databases such as EMBASE, PubMed, Medline, Web of Sciencethe and Cochrane Library. When searching, we use the following keywords and their combinations $₫$ staples, clips, suture, arthroplasty, hip, wound, closure and skin. Our study included only English-language publications on human trials. In addition, the bibliographies of the included studies and dissertations were searched for additional publications. Hand-search of relevant trials, reviews and related articles were also performed. Authors were contacted when possible to obtain missing information.

\section{Inclusion and exclusion criteria}

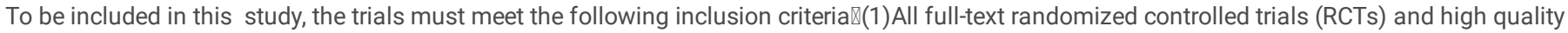
retrospective cohort studies;(2)staples versus sutures;(3)patients treated with primary hip arthroplasty, included total hip arthroplasty and hemiarthroplasty; (4)the study provided at least one of the key outcome. Here are the exclusion criteria for our article:(1)skin adhesives as a primary or adjunct means of skin closure(2)barbed suture(3) Case reports, discourses, basic research, conference papers, non-English articles and other studies that do not contain the results 
of our interest;(4) data that could not be extracted. How deeper tissues were closed, the type of suture or stitch technique are not our exclusion criteria. The two authors independently assessed whether the article met the criteria for inclusion, and then discussed their differences until they reached a consensus.

\section{Selection of the Literature}

After eliminating duplicates, two independent researchers (Zirui Liu,Binfeng Liu) scanned titles and abstracts according to predetermined selection criteria and selected randomized controlled trials that might be relevant. Retrieve hard copies of all relevant articles and read the full text for further identification. Relevant data are extracted through a pre-determined standardized procedure involving the first author, the year of publication, the demographic characteristics of countries, participants and treatment options for each group..

\section{Quality Assessment}

Cochrane collaboration tool for assessing risk of bias was used to evaluate the methodological quality of the included randomized controlled trials(21). This tool focuses on the internal validity of the trial and assessment of risk of possible bias in different phases of the trial. The details are as follows: random sequence generation, allocation concealment, blinding of outcome assessment, blinding of participants and personnel, incomplete outcome data, selective reporting, and other bias. Each item was classified according to a high, low, or unclear risk of bias that is represented as high $(\mathrm{H})$, low $(\mathrm{L})$, and unclear $(\mathrm{U})$, respectively. The Newcastlee-Ottawa Scale (NOS) was used to assess the quality of cohorts and case-control studies.(22). NOS ranges from 0 to 9 stars; research scores above 5 are considered high quality. All of the assessments were conducted by 2 independent reviewers (Zirui Liu $\varangle$ Binfeng Liu).

\section{Data Extraction}

The relevant data from the eligible papers were double extracted by author (Zirui Liu, Hao Yang) according to a predefined standardized protocol. We extracted the baseline of each included study from trials included the following information: design, closure material, age(mean), sex, cohort size, follow-up, information on study objective. When inadequate information existed in the studies, contacting the 1 st authors to obtain and clarify the relevant data were essential as specified by the standardized protocol.

\section{Outcome Assessment}

We extracted infection, Prolonged discharge, abscess, wound dehiscence, allergic reaction, inflammation as our primary evaluated outcome. Secondary outcomes evaluated included Wound Closure time, length of stay in hospital, Hollander Wound Evaluation score, visual analogue scale.

\section{Statistical Analysis}

The Review Manager Software Package (RevMan Version5.3, The Cochrane Collaboration, Copenhagen, 2014) was used to generate forest plots. The overall effect of staples or sutures for wound closure was calculated as the weighted average of the inverse variance adjusted individual effects and $95 \%$ confidence

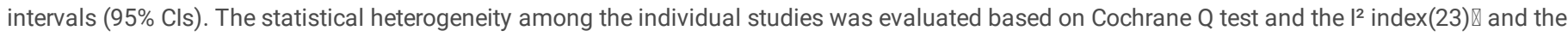
statistical heterogeneity was confirmed if $\mathrm{I}^{2}$ was $>50 \%$ and $\mathrm{P}<0.10(24)$. A variance-based fixed effect model was applied to calculate the pooled effect; otherwise, a random effect model was used in the presence of statistically significant heterogeneity(25). If appropriate, the heterogeneity was identified and explained using a subgroup analysis(23). Evidence grading was evaluated according to the Grading of Recommendations, Assessment, Development, and Evaluation system(26).

\section{Ethical Statement}

As all analyses were grounded on previously published studies, ethical approval was not necessary.

\section{Result}

\section{Literature search}

There were 2102 articles in the initial literature search. According to inclusion and exclusion criteria, A total of 155 articles were screened through duplicates checking and title and abstract screening. Finally, after careful reading of the full text, four randomized controlled trials $(6,11,12,27)$ and one retrospective cohort trial(13) were included in our study. The flowchart process of screened and selected trials was presented in Figure 1.

\section{Characteristics of the trials}

A total of 751 patients: 359 in the staples group and 392 in the sutures group were recruited in our study. Every patient we selected from this eligible study underwent total hip replacement or hemiarthroplasty. A RCT(27) is divided into three groups: skin clips group, OCA(2-octylcyanoacrylate) group and suture group. The OCA group was excluded from this meta-analysis. The retrospective cohort trials(13) also divided into three groups: subcuticular suture group, staple group and interrupted suture group. Due to staples were used in subcuticular suture group as a supplementary means of skin closure, so we also remove subcuticular suture group from this meta-analysis. There was no difference in demographic and clinical data among each study. The mean age of the participants range from 55.7 years to 71 years in the staples groups and 57.8 years to 69 years in the suture groups. The sample size of our included study was range from 17 to 141 . More detailed baseline characteristics of eligible studies are shown in Table 1.

\section{Risk of bias assessment}


Based on the Cochrane Collaboration recommendation, three RCTs $(11,12,27)$ reported the detailed methods of random sequence generation. Two RCTs(12, 27) reported allocation concealments. the participants and personnel were blinded in $3 \operatorname{RCTs}(6,12,27)$. In addition, full details of withdrawals and dropouts were described in all studies. In some studies, the follow-up rate was $100 \%$. Details of deviation risk are shown in Figure 2 . The bias risk of retrospective cohort trials assessed with NOS is shown in Table 2.

\section{Infection}

All the trials included in our study compare the infection rates between staples group and suture, regardless of superficial or deep infection. 11 out of 359 patients in the staples group were infected, while 2 out of 392 patients in the suture group. The fixed-effects meta-analysis of 5 trials showed that the risk of infection higher with staples than with sutures for skin closure after hip arthroplasty. The Odds Ratio of infection was $3.57(95 \% \mathrm{Cl}, 1.15$ to $11.05 ; \mathrm{P}=0.03)$ and there was no heterogeneity $\left(\chi^{2}=2.45 ; I^{2}=0 \% ; p=0.65\right)$. The Forest plot are illustrated in Supplemental in Figure 3. In addition , we further compared the infection rate between with staples and with suture for skin closure after total hip arthroplasty. Data regarding infection after total hip arthroplasty were reported in three studies $(11,12,27)$. After total hip arthroplasty, 5 out of 231 patients in the staples group were infected, while 1 out of 234 patients in the suture group. However, The fixed-effects meta-analysis showed no significant difference in infection rate between two groups after total hip arthroplasty, with OR(Odds Ratio) of $2.61(95 \% \mathrm{Cl} 0.60$ to $11.41 ; p=0.20)$ and no heterogeneity $\left(\chi^{2}=2.10 ; I^{2}=5 \% ; P=0.35\right)$. The Forest plot are illustrated in Figure 4. All Pooled outcomes comparing staples to suture for skin closure after arthroplasty are listed in Table 3.

\section{Discharge}

Overall 4 studies $(6,11,13,27)$ reported the discharge after hip arthroplasty. All of them show there were no significant difference in discharge rate after hip arthroplasty between staples group and suture group. However, the fixed-effects meta-analysis of all 4 trials revealed that the risk of discharge lower with suture than with staples for skin closure after hip arthroplasty. The Odds Ratio of discharge was $2.73(95 \% \mathrm{Cl}, 1.07$ to $6.95 ; \mathrm{P}=0.03)$, and there was no heterogeneity $\left(\chi^{2}=1.43 ; l^{2}=0 \% ; p=0.70\right)$. The Forest plot is listed in Figure 5.

\section{Abscess}

Two study $(13,27)$ compared number of participant whose wound formed an abscess after hip arthroplasty. A total of 321 patients, only one of patient in suture group formed an abscess. The OR-based models revealed that skin staples were associated with a similar abscess rate to an sutures $(\mathrm{OR}=0.30 ; 95 \% \mathrm{Cl}$ $0.01-7.54 ; P=0.46)$ with no heterogeneity. The Forest plot are illustrated in Figure 6.

\section{Wound dehiscence}

Data regarding wound dehiscence were reported in two studies $(12,13)$. Only one patient had a wound dehiscence. The fixed-effects meta-analysis of 2 trials revealed that there was no significant difference in the risk of wound dehiscence between the two group after hip arthroplasty $(\mathrm{OR}=0.42 ; 95 \% \mathrm{Cl} 0.02-10.41$; $\mathrm{P}=0.60$ ) with no heterogeneity. The Forest plot are illustrated in Figure 6.

\section{Allergic reaction}

There were two trials $(11,27)$ reported the allergic reaction. Two out of 300 patients appear allergic reaction and our finding shows that there was no significant difference in the risk of wound dehiscence between staples group and suture group after hip arthroplasty $(\mathrm{OR}=0.39 ; 95 \% \mathrm{Cl} 0.09-1.69$; $P=0.21$, heterogeneity: $\left.\chi^{2}=0.03, P=0.86, I^{2}=0 \%\right)$. The Forest plot are illustrated in Figure 6.

\section{Inflammation}

A total of two trials $(6,13)$ reported inflammation. In staples group, there were sign of inflammation in 12 patients from 128 participant, while only were seven patients from 158 participant have the sign of inflammation. However, our pooled result revealed that the differences noted between group $A$ and group $B$ were not statistically significant(OR=3.78; $95 \% \mathrm{Cl} 0.05317 .93 ; \mathrm{P}=0.56$; heterogeneity: $\left.\chi^{2}=7.43, \mathrm{P}=0.006, \mathrm{I}^{2}=87 \%\right)$. Because the heterogeneity is more than $50 \%$, so we choose the fixed-effects model. In addition, there is no more data to support our further sensitivity or subgroup analysis. The Forest plot are illustrated in Figure 7.

\section{Systematic Review}

In addition to the six outcomes assessed in our study, four other secondary outcomes (length of stay, Holland Wound Assessment Score, closure time and visual analogue score) were compared in the systematic review section of our study. Because these included trials do not provide appropriate data types to conduct a meta-analysis.

Wound closure time $\ T$ wo studies reported the time required to close different layers of tissue. Khan, R. J.et al(27) and Rui, M.et al(12) both indicated that wound closure with skin staples was significantly faster than with suture. The data about wound closure time with skin staples or suture are listed in Table 4.

Length of stay: Three studies indicated the length of stay in hospital for wound closure with skin staples or suture after hip arthroplasty. Khan, R. J.et $\mathrm{al}(27)$ and Lu, Y.et al(13) both showed that there were no significant difference in the median length of stay in hospital. However, Rui, M.et al(12) reported length of stay in hospital in staples group compared with suture group. The median and Interquartile range of length of stay in hospital are listed in Table 4.

HWES (Hollander Wound Evaluation Score): There were two studies used Hollander Wound Evaluation Score to evaluate wound after hip arthroplasty. In the two articles $(12,27)$, The HWES of staples group was lower than that of suture group, but there was no significant difference in Holland's wound evaluation score. The Hollander Wound Evaluation Score are listed in Table 4. 
VAS(visual analogue scale): Two studies $(12,27)$ use visual analogue scale(VAS) to evaluate satisfaction of patients with skin wound closure methods. the study Khan et al judged that patient satisfaction with skin closure technology was assessed with the Visual Analogue Scale (VAS) between 0 and 100 , of which 100 expressed the greatest satisfaction, while Rui, M et al was assessed with the Visual Analogue Scale (VAS) between 0 and 10 expressed the greatest satisfaction, of which 10 indicated the greatest satisfaction. Both of them reported that there was no significant difference in the satisfaction of patients for staples group and suture group after hip arthroplasty. The Visual Analogue Scale (VAS) are listed in Table 4.

\section{Discussion}

Hip arthroplasty is the ultimate treatment for debilitating hip joint disease. In recent years, the number of hip replacement has been increasing. (2). The main goal of the skin closure in hip arthroplasty is to obtain an adequate closure and fast healing, with an acceptable appearance and to reduce complications; delayed healing, dehiscence, hematoma and infection $(10,28)$. There are many kinds of skin closure methods in hip arthroplasty, staples and sutures have served as a primary method of superficial skin closure in hip arthroplasty(29). At present囚There is no clear clinical guideline for the method skin closure after hip arthroplasty. Overall, our aim of this system review and meta-analysis was to provided valuable information about Sutures versus staples for wound closure in hip arthroplasty. In the present study $₫$ we evaluated infection, prolonged discharge, abscess, wound dehiscence, allergic reaction, inflammation, wound closure time, length of stay in hospital, Hollander Wound Evaluation Score, patient's satisfaction with skin closure methods from four eligible RCTs and one retrospective cohort trial that compared outcomes with staples or suture for skin wound closure after hip arthroplasty.

In the present study, we find that the risk of infection with sutures was less than three times that with staples for skin closure after hip arthroplasty. However, all the studies we have included show that there was no significant difference in the risk of infection after hip arthroplasty comparing sutures to staples was found. We find our pooled result were similar to a previous meta-analysis by Smith, T. O. et al(19), they reported that after orthopedics surgery, the risk of wound infection is significantly higher when the skin wound is closed with staples rather than suture, especially in patients who undergo hip surgery. Meanwhile, the study Shetty et al(30) also showed that the incidence of superficial wound infection was significantly higher when metal staples were used to suture skin wounds after hip fractures. In addition, our meta-analysis show that there were no significant difference in the infection rate between two groups after total hip arthroplasty, which were consistent with three RCTs. Surgical site infection increases the burden of the health care system, increases the length of stay, re-hospitalization rate and the cost of health care, and adversely affects the quality of life and function of patients(31). So our meta-analysis results may be helpful for the choice of skin wound closure methods between staples and suture for hip arthroplasty. However, there are still some potential prognostic factors that remain uncertain. For example, surgical techniques, expertise, aseptic techniques, antibiotic time and patient-specific prognostic factors (such as body mass index) may also influence surgical site infection risk(32). So we need more high quality randomization, blinding, adequate length of follow-up RCTs to be published and then included in our analysis to help us choose skin wound closure methods between staples and suture after hip arthroplasty. In the meantime, our finding suggests that the prolonged wound discharge rate was significant lower in suture group. But all of the included studies in this study were report that there was no significant difference when compared discharge rate between staples group and suture group. Our result and other previous study show that the skin wound closed with staples was more resistant to infection and then affect wound healing and wound discharge(33). Beside, many potential factors, such as the accuracy of skin of the dermal margins and doctor's skill, may affect the exudation of wound discharge(34).

In addition, we compare the incidence of abscess, wound dehiscence, allergic reaction and inflammation between the two group and our analysis found that there were no significant difference in this outcome between the staples group and suture group. Our result lends support to the conclusions by Krishnan, R. et $\mathrm{al}(18)$ in which they reported that there no significant difference in allergic reaction, inflammation, dehiscence, and abscess formation between the two groups after orthopedic surgery. However, it is important to note that only two RCTs analyzed LOS (Length of stay), allergic reaction, inflammation, dehiscence, and abscess formation between the two groups. Finally, our systematic review results show that there was no significant difference in HWES and patient's satisfaction with skin wound closure methods after hip arthroplasty. So this is not the factor that affects our choice of skin closure methods after hip arthroplasty. Khan, R. J.et al(27) and Lu, Y.et al(13) both showed that there were no significant difference in the median length of stay in hospital. However, Rui, M.et al(12) reported the median(interquartile range) of length of stay in hospital(day) in staples group was 12(11-13) and 6.0(5-8) in sutures group. The results do suggest that the length of hospitalization of the suture needle may be slightly longer than that of skin suture. Khan et al(27) reported an estimated two-minute savings in skin suture with staples for skin closure. Rui, M(12) also reported that the use of staples for skin closure can save about five minutes compared with sutures. The results do suggest that the use of suture needles may be slightly faster than that of skin sutures after hip arthroplasty.

Although this analysis selected 5 studies $囚$ the different studies comparison outcome with different method, we try our best to analyze the data that can be included. The limitations of this meta-analysis and systematic review involve restrictions on the small number of included high-quality RCTs, Unified surgical management program and rehabilitation program as well as publishing language. Some literatures or guides have well documented the distorting effects of location bias and publication bias on system evaluation and meta-analysis(35-37). The poor quality of evidence methods reduces the quality of evidence in meta-analysis. Because of some characteristics of surgical techniques, orthopedic surgeons can not cause blindness. Therefore, attention should be paid to interpreting the estimates of this meta-analysis. Future research should focus on high-quality randomized controlled trials. Detailed baseline characteristics and detailed patient recruitment flow charts should be provided.

\section{Conclusion}

In summary $囚$ the meta-analyses and systematic reviews suggested that the risk of infection and prolonged discharge higher with staples than with sutures for skin closure after hip arthroplasty. Meanwhile, there was no significant difference in allergic reaction, inflammation, dehiscence, abscess formation, Hollander Wound Evaluation Score and satisfaction of patients with skin wound closure methods between the two groups after hip arthroplasty. However, the suture group may require operating surgical time. 


\section{Abbreviations List}

SSIs - Surgical site infections

RCTs - randomized controlled trials

H-high

L - low

U- unclear

NOS - Newcastlee-Ottawa scale

95\% Cls - 95\% confidence intervals

OCA-2-octylcyanoacrylate

OR-Odds Ratio)

HWES -Hollander Wound Evaluation Score

VAS-visual analogue scaleAR-Androgen Receptor

LOS -Length of stay

\section{Declarations}

\section{Competing interests}

The author(s) declare no competing interests.

\section{Acknowledgments}

This work was supported by 2017 Key scientific and technological projects in Henan Province : Development and basic clinical study of internal fixation guide

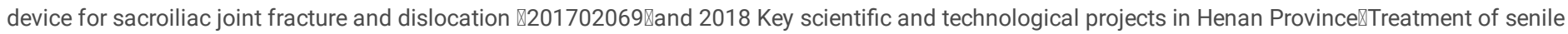
kyphosis with 3D printing osteotomy guide plate combined with bone cement nail track $2018020041 \rrbracket$

\section{Ethics approval and consent to participate}

Not applicable

\section{Consent for publication}

Not applicable.

\section{Availability of data and material}

All data and material generated or analyzed during this study are included in this published article (and its Supplementary Information files).

\section{Competing interests}

The author(s) declare no competing interests.

\section{Funding}

Key scientific and technological projects in Henan Province

\section{Authors' contributions}

study design, data analysis, writing: Zirui Liu

data collections, data analysis: Hao Yang,Binfeng Liu

study design: Liang Zhao

\section{References}

1. Han Y, Yang W, Pan J, Zeng L, Liang G, Lin J, et al. The efficacy and safety of knotless barbed sutures in total joint arthroplasty: a meta-analysis of randomized-controlled trials. Arch Orthop Trauma Surg. 2018;138(10):1335-45. 
2. Kurtz SM, Ong KL, Lau E, Bozic KJ. Impact of the economic downturn on total joint replacement demand in the United States: updated projections to 2021. J Bone Joint Surg Am. 2014;96(8):624-30.

3. Hopley C, Stengel D, Ekkernkamp A, Wich M. Primary total hip arthroplasty versus hemiarthroplasty for displaced intracapsular hip fractures in older patients: systematic review. BMJ. 2010;340:c2332.

4. Kurtz S, Ong K, Lau E, Mowat F, Halpern M. Projections of primary and revision hip and knee arthroplasty in the United States from 2005 to 2030 . J Bone Joint Surg Am. 2007;89(4):780-5.

5. Clayer M, Southwood RT. Comparative study of skin closure in hip surgery. Aust N Z J Surg. 1991;61(5):363-5.

6. Singh B, Mowbray MAS, Nunn G, Mearns S. Closure of hip wound, clips or subcuticular sutures: does it make a difference? Eur J Orthop Surg Traumatol. 2006;16(2):124-9.

7. Gaine WJ, Ramamohan NA, Hussein NA, Hullin MG, McCreath SW. Wound infection in hip and knee arthroplasty. J Bone Joint Surg Br. 2000;82(4):561-5.

8. Dowsey MM, Kilgour ML, Santamaria NM, Choong PF. Clinical pathways in hip and knee arthroplasty: a prospective randomised controlled study. Med J Aust. 1999;170(2):59-62.

9. Patel RM, Cayo M, Patel A, Albarillo M, Puri L. Wound complications in joint arthroplasty: comparing traditional and modern methods of skin closure. Orthopedics. 2012;35(5):e641-6.

10. Slade Shantz JA, Vernon J, Morshed S, Leiter J, Stranges G. Sutures versus staples for wound closure in orthopaedic surgery: a pilot randomized controlled trial. Patient Saf Surg. 2013;7(1):6.

11. Buttaro MA, Quinteros M, Martorell G, Zanotti G, Comba F, Piccaluga F. Skin staples versus intradermal wound closure following primary hip arthroplasty: a prospective, randomised trial including 231 cases. Hip Int. 2015;25(6):563-7.

12. Rui M, Zheng X, Sun SS, Li CY, Zhang XC, Guo KJ, et al. A prospective randomised comparison of 2 skin closure techniques in primary total hip arthroplasty surgery. Hip Int. 2018;28(1):101-5.

13. Lu Y, Wang C, Lin L, Qin Q, Li Q. Complication rate of different wound closures after primary hip arthroplasty - A survey of 373 patients. Asia Pac J Sports Med Arthrosc Rehabil Technol. 2018;11:15-8.

14. Ranaboldo CJ, Rowe-Jones DC. Closure of laparotomy wounds: skin staples versus sutures. Br J Surg. 1992;79(11):1172-3.

15. Kanegaye JT, Vance CW, Chan L, Schonfeld N. Comparison of skin stapling devices and standard sutures for pediatric scalp lacerations: a randomized study of cost and time benefits. J Pediatr. 1997;130(5):808-13.

16. Barrow J, Divecha H, Board T. Skin closure in arthroplasty surgery: Current practice. Int Wound J. 2018;15(6):966-70.

17. Kim KY, Anoushiravani AA, Long WJ, Vigdorchik JM, Fernandez-Madrid I, Schwarzkopf R. A Meta-Analysis and Systematic Review Evaluating Skin Closure After Total Knee Arthroplasty-What Is the Best Method? J Arthroplasty. 2017;32(9):2920-7.

18. Krishnan R, MacNeil SD, Malvankar-Mehta MS. Comparing sutures versus staples for skin closure after orthopaedic surgery: systematic review and metaanalysis. BMJ Open. 2016;6(1):e009257.

19. Smith TO, Sexton D, Mann C, Donell S. Sutures versus staples for skin closure in orthopaedic surgery: meta-analysis. BMJ. 2010;340:c1199.

20. Krishnan RJ, Crawford EJ, Syed I, Kim P, Rampersaud YR, Martin J. Is the Risk of Infection Lower with Sutures than with Staples for Skin Closure After Orthopaedic Surgery? A Meta-analysis of Randomized Trials. Clin Orthop Relat Res. 2019;477(5):922-37.

21. Michaelis R, Tang V, Wagner JL, Modi AC, Curt LaFrance W, Jr., Goldstein LH, et al. Cochrane systematic review and meta-analysis of the impact of psychological treatments for people with epilepsy on health-related quality of life. Epilepsia. 2018;59(2):315-32.

22. G.A. Wells, B. Shea, D. O'Connell, J. Peterson, V. Welch, M. Losos. The NewcastleeOttawa Scale (NOS) for Assessing the Quality of Non-randomized Studies in Meta-analysis.

23. Melsen WG, Bootsma MC, Rovers MM, Bonten MJ. The effects of clinical and statistical heterogeneity on the predictive values of results from metaanalyses. Clin Microbiol Infect. 2014;20(2):123-9.

24. Higgins JP, Thompson SG, Deeks JJ, Altman DG. Measuring inconsistency in meta-analyses. BMJ. 2003;327(7414):557-60.

25. DerSimonian R, Laird N. Meta-analysis in clinical trials revisited. Contemp Clin Trials. 2015;45(Pt A):139-45.

26. Balshem H, Helfand M, Schunemann HJ, Oxman AD, Kunz R, Brozek J, et al. GRADE guidelines: 3. Rating the quality of evidence. J Clin Epidemiol. 2011;64(4):401-6. 
27. Khan RJ, Fick D, Yao F, Tang K, Hurworth M, Nivbrant B, et al. A comparison of three methods of wound closure following arthroplasty: a prospective, randomised, controlled trial. J Bone Joint Surg Br. 2006;88(2):238-42.

28. Ercole FF, Chianca TC, Duarte D, Starling CE, Carneiro M. Surgical site infection in patients submitted to orthopedic surgery: the NNIS risk index and risk prediction. Rev Lat Am Enfermagem. 2011;19(2):269-76.

29. Livesey C, Wylde V, Descamps S, Estela CM, Bannister GC, Learmonth ID, et al. Skin closure after total hip replacement: a randomised controlled trial of skin adhesive versus surgical staples. J Bone Joint Surg Br. 2009;91(6):725-9.

30. Shetty AA, Kumar VS, Morgan-Hough C, Georgeu GA, James KD, Nicholl JE. Comparing wound complication rates following closure of hip wounds with metallic skin staples or subcuticular vicryl suture: a prospective randomised trial. J Orthop Surg (Hong Kong). 2004;12(2):191-3.

31. Whitehouse JD, Friedman ND, Kirkland KB, Richardson WJ, Sexton DJ. The impact of surgical-site infections following orthopedic surgery at a community hospital and a university hospital: adverse quality of life, excess length of stay, and extra cost. Infect Control Hosp Epidemiol. 2002;23(4):183-9.

32. de Jonge SW, Gans SL, Atema JJ, Solomkin JS, Dellinger PE, Boermeester MA. Timing of preoperative antibiotic prophylaxis in 54,552 patients and the risk of surgical site infection: A systematic review and meta-analysis. Medicine (Baltimore). 2017;96(29):e6903.

33. Thakore RV, Greenberg SE, Shi H, Foxx AM, Francois EL, Prablek MA, et al. Surgical site infection in orthopedic trauma: A case-control study evaluating risk factors and cost. J Clin Orthop Trauma. 2015;6(4):220-6.

34. Meiring L, Cilliers K, Barry R, Nel CJ. A comparison of a disposable skin stapler and nylon sutures for wound closure. S Afr Med J. 1982;62(11):371-2.

35. Egger M, Smith GD. Bias in location and selection of studies. BMJ. 1998;316(7124):61-6.

36. Ernst E, Pittler MH. Alternative therapy bias. Nature. 1997;385(6616):480.

37. Sood A, Knudsen K, Sood R, Wahner-Roedler DL, Barnes SA, Bardia A, et al. Publication bias for CAM trials in the highest impact factor medicine journals is partly due to geographical bias. J Clin Epidemiol. 2007;60(11):1123-6.

\section{Tables}

Table 1: The characteristics of included studies

\begin{tabular}{|c|c|c|c|c|c|c|c|c|c|c|c|}
\hline \multirow[t]{2}{*}{ Author/year } & \multirow[t]{2}{*}{ Period } & \multirow[t]{2}{*}{ Study } & \multirow[t]{2}{*}{ Operation } & \multirow{2}{*}{$\begin{array}{l}\text { Closure } \\
\text { material }\end{array}$} & \multicolumn{2}{|l|}{ Size } & \multicolumn{2}{|c|}{ Age『mean! } & \multicolumn{2}{|c|}{ SEX (male) } & \multirow{2}{*}{$\begin{array}{l}\text { Follow- } \\
\text { up(days) }\end{array}$} \\
\hline & & & & & staples & sutures & staples & sutures & staples & sutures & \\
\hline \multirow[t]{2}{*}{ Khan/2006 } & 2004 & $\mathrm{RCT}$ & THA & $\begin{array}{l}3.0 \\
\text { poliglecaprone }\end{array}$ & 36 & 33 & 71 & 69 & $20 / 36$ & $17 / 33$ & $56-84$ \\
\hline & & & & $\begin{array}{l}\text { Suture, skin } \\
\text { staples }\end{array}$ & & & & & & & \\
\hline \multirow[t]{2}{*}{ Singh/2006 } & $\begin{array}{l}2001- \\
2002\end{array}$ & $\mathrm{RCT}$ & THA, hemiarthroplasty & $\begin{array}{l}\text { Subcuticular } \\
\text { vicryl }\end{array}$ & 17 & 17 & \multirow{2}{*}{\multicolumn{2}{|c|}{ Unclear }} & \multirow{2}{*}{\multicolumn{2}{|c|}{ Unclear }} & $2,5,7,10,14$ \\
\hline & & & & skin clips & & & & & & & \\
\hline Patel/2012 & $\begin{array}{l}2009- \\
2010\end{array}$ & $\mathrm{RC}$ & THA, hemiarthroplasty & $\begin{array}{l}3.0 \text { Biosyn, } \\
\text { staples }\end{array}$ & 81 & 21 & \multicolumn{2}{|l|}{ Unclear } & \multicolumn{2}{|l|}{ Unclear } & $14,28,56$ \\
\hline Buttaro/2015 & $\begin{array}{l}2011- \\
2012\end{array}$ & $\mathrm{RCT}$ & THA & $\begin{array}{l}3.0 \\
\text { polypropylene } \\
\text { suture『staples }\end{array}$ & 112 & 119 & \multicolumn{2}{|c|}{62 (range 21-91) } & \multicolumn{2}{|l|}{ Unclear } & 15,45 \\
\hline Lu, Y/2018 & $\begin{array}{l}2013- \\
2015\end{array}$ & $\mathrm{RC}$ & THA, hemiarthroplasty & $\begin{array}{l}\text { Nylon sutures, } \\
\text { staples }\end{array}$ & 111 & 141 & 64.1 & 67.3 & $53 / 111$ & $56 / 141$ & 30 \\
\hline \multirow[t]{2}{*}{ Rui, M/2018 } & $\begin{array}{l}2014- \\
2015\end{array}$ & RCT & THA & $\begin{array}{l}4.0 \\
\text { absorbable }\end{array}$ & 83 & 82 & 55.7 & 57.8 & $36 / 83$ & $39 / 82$ & 90,365 \\
\hline & & & & $\begin{array}{l}\text { subcuticular } \\
\text { suture, staples }\end{array}$ & & & & & & & \\
\hline
\end{tabular}

The characteristics of all included studies

RC: retrospective cohort; RCT: randomised controlled trial; THA: total hip arthroplasty

Table 2: Risk of bias assessment of retrospective cohort trial 


\begin{tabular}{|ll|}
\hline Risk of bias assessment & Lu, Y, et al. (2018) \\
\hline Selection & 3 \\
Comparability & 2 \\
\hline Outcome/exposure & 2 \\
\hline Total score & 7 \\
\hline
\end{tabular}

Footnotes: the Newcastle Ottawa scale (NOS) was used to assess the quality of nonrandomized studies with its design, content and ease of use directed to the task of incorporating the quality assessments in the interpretation of meta-analytic results.

Table 3: Pooled outcomes comparing staples to suture for skin closure after arthroplasty

\begin{tabular}{|c|c|c|c|c|c|c|c|}
\hline \multirow[t]{2}{*}{ Outcomes } & \multirow[t]{2}{*}{ NO.of studies } & \multicolumn{2}{|c|}{ NO.of case } & \multirow[t]{2}{*}{$\mathrm{OR}(95 \% \mathrm{Cl})$} & \multirow[t]{2}{*}{$P$ value } & \multicolumn{2}{|c|}{ Heterogeneity } \\
\hline & & Staples & Suture & & & $\mathrm{I}^{2}(\%)$ & $P$ value \\
\hline Infection & 5 & $11 / 359$ & $2 / 392$ & $3.57(1.15,11.05)$ & $0.03^{*}$ & 0 & 0.65 \\
\hline Infection(THA) & 3 & $5 / 231$ & $1 / 234$ & $2.61(0.60,11.41)$ & 0.20 & 5 & 0.35 \\
\hline Prolonged discharge & 4 & $15 / 276$ & $6 / 310$ & $2.73(1.07,6.95)$ & $0.03^{*}$ & 0 & 0.70 \\
\hline Abscess & 2 & $0 / 147$ & $1 / 174$ & $0.30(0.01,7.54)$ & 0.46 & \multicolumn{2}{|c|}{ Not applicable } \\
\hline Wound dehiscence & 2 & $0 / 194$ & $1 / 223$ & $0.42(0.02,10.41)$ & 0.60 & \multicolumn{2}{|c|}{ Not applicable } \\
\hline Allergic reaction & 2 & $2 / 148$ & $6 / 152$ & $0.39(0.09,1.69)$ & 0.21 & 0 & 0.86 \\
\hline Inflammation & 2 & $12 / 128$ & $7 / 158$ & $3.78(0.05,317.93)$ & 0.56 & 87 & 0.006 \\
\hline
\end{tabular}

THA: total hip arthroplasty, OR: odds ratio; The outcome of inflammation was calculated using the Mental-Haeszel random-effects model. Others outcome were calculated using the Mental-Haeszel fixed-effects model. *: p value $<0.05$.

Table 4: Closure time『LOS®HWES®VAS

\begin{tabular}{|c|c|c|c|c|c|c|}
\hline \multirow[t]{2}{*}{ Outcomes } & \multirow[t]{2}{*}{ Author/Year } & \multicolumn{2}{|l|}{ Staples } & \multicolumn{2}{|l|}{ Suture } & \multirow[t]{2}{*}{$P$ value } \\
\hline & & Median & Interquartile range & Median & Interquartile range & \\
\hline \multicolumn{7}{|c|}{ Closure time(s) } \\
\hline & Khan/2006 & 30 & $18-30$ & 150 & 210 & NA \\
\hline & Rui, M/2018 & 24.7 & 21.3-29.4 & 357.7 & $332.1-383.1$ & $p<0.001$ \\
\hline \multicolumn{7}{|l|}{ LOS(day) } \\
\hline & Khan/2006 & 4 & $3-6$ & 4 & $4-6$ & NA \\
\hline & Lu, Y/2018* & 16.9 & 8-30(range) & 17.3 & 9-35(range) & NA \\
\hline & Rui, M/2018 & 12 & $11-13$ & 6.0 & $5-8$ & $p<0.001$ \\
\hline \multicolumn{7}{|l|}{ HWES } \\
\hline & Khan/2006 & 5.3 & $5-6$ & 6 & $5-6$ & NA \\
\hline & Rui, M/2018 & 4 & $4-5$ & 5 & $4-5$ & 0.170 \\
\hline \multicolumn{7}{|l|}{ VAS** } \\
\hline & Khan/2006 & 95 & $88-100$ & 94 & $86-99$ & NA \\
\hline & Rui, M/2018 & 6 & $6-8$ & 7 & $6-8$ & 0.180 \\
\hline
\end{tabular}

NA: not applicable; LOS: length of stay; HWES: Hollander Wound Evaluation score; VAS: Visual Analogue Scale.

*: the study Lu, Y et al provides only the median and range of length of stay, not Interquartile range. **: the study Khan et al judged that patient satisfaction with skin closure technology was assessed with the Visual Analogue Scale (VAS) between 0 and 100, of which 100 expressed the greatest satisfaction, while Rui, $M$ et al was assessed with the Visual Analogue Scale (VAS) between 0 and 10 expressed the greatest satisfaction, of which 10 indicated the greatest satisfaction.

\section{Figures}




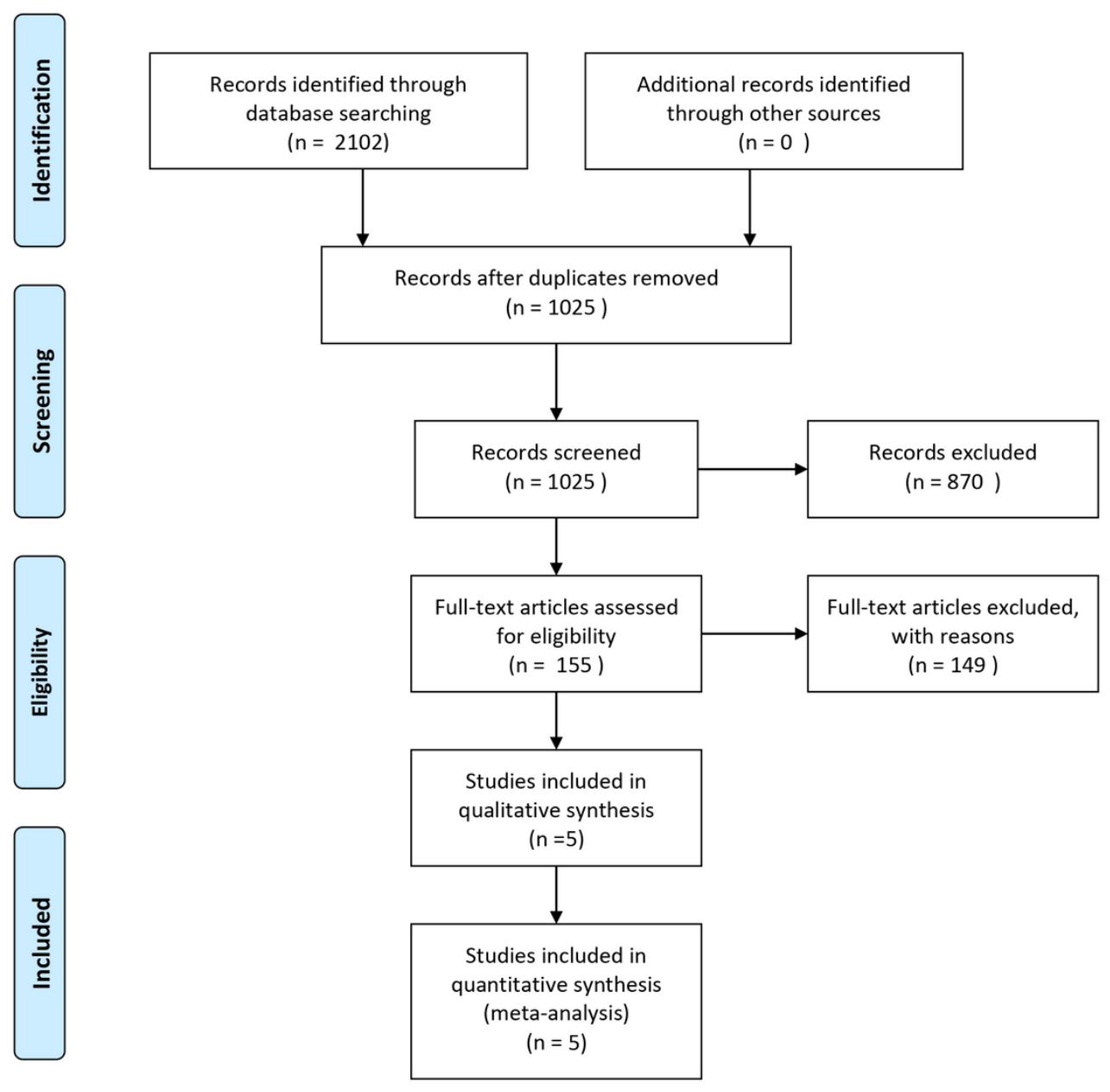

Figure 1

Flow diagram of the studies included 


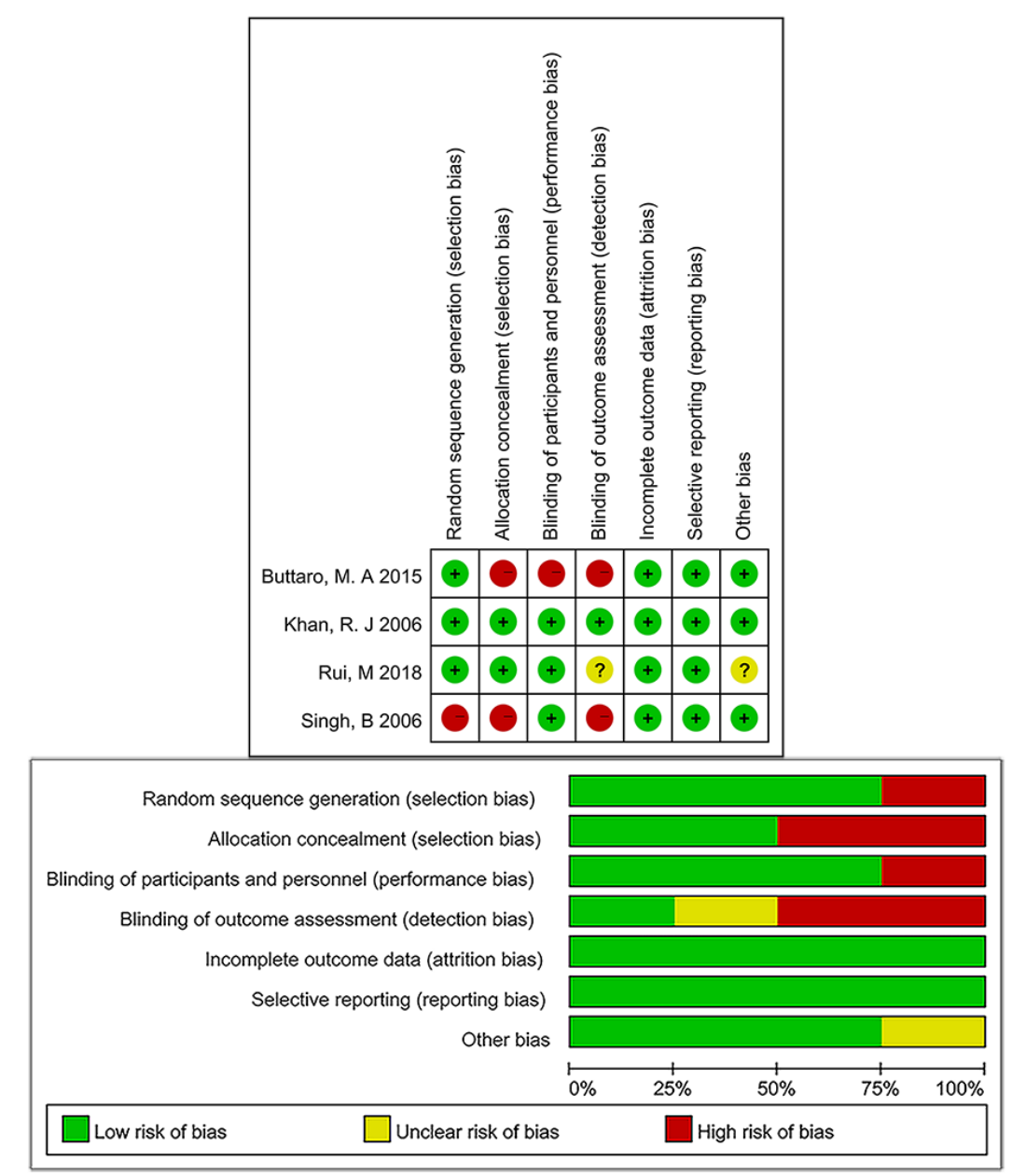

Figure 2

Risk of bias summary and graph of randomized controlled trials

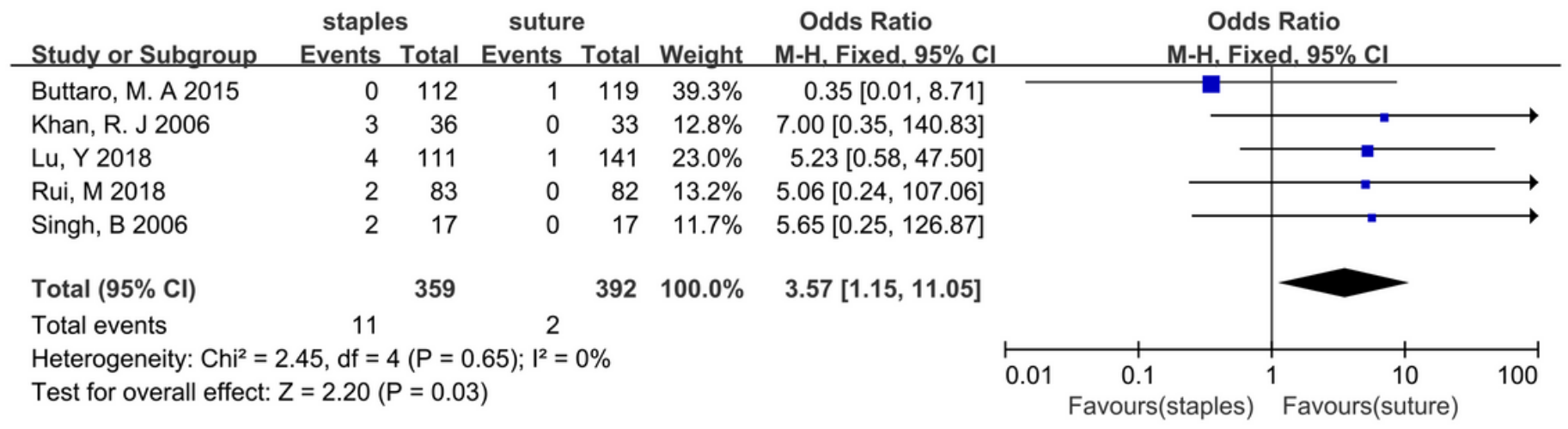

Figure 3

Forest plot for infection rate after hip arthroplasty 


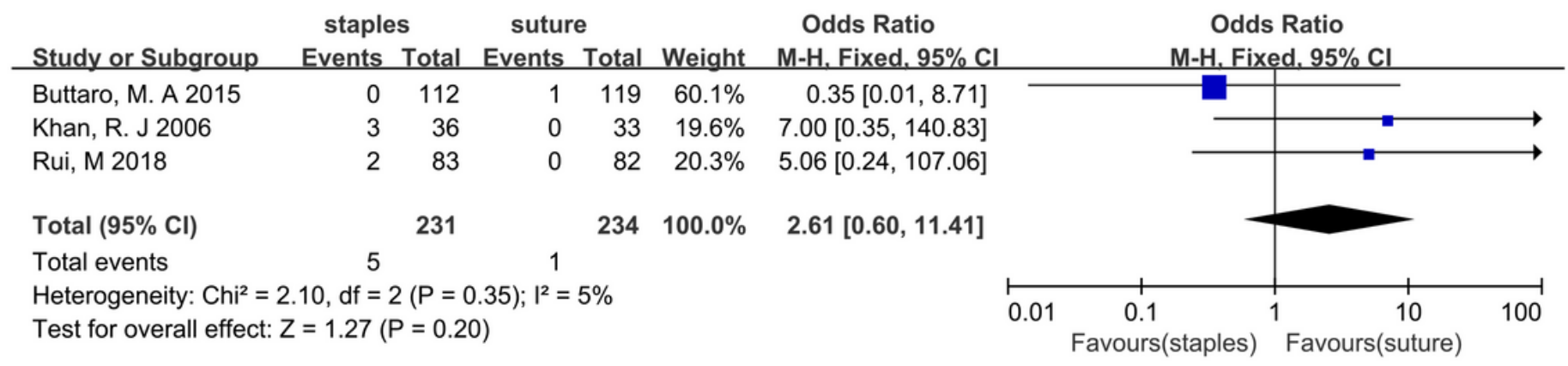

Figure 4

Forest plot for infection rate after total hip arthroplasty

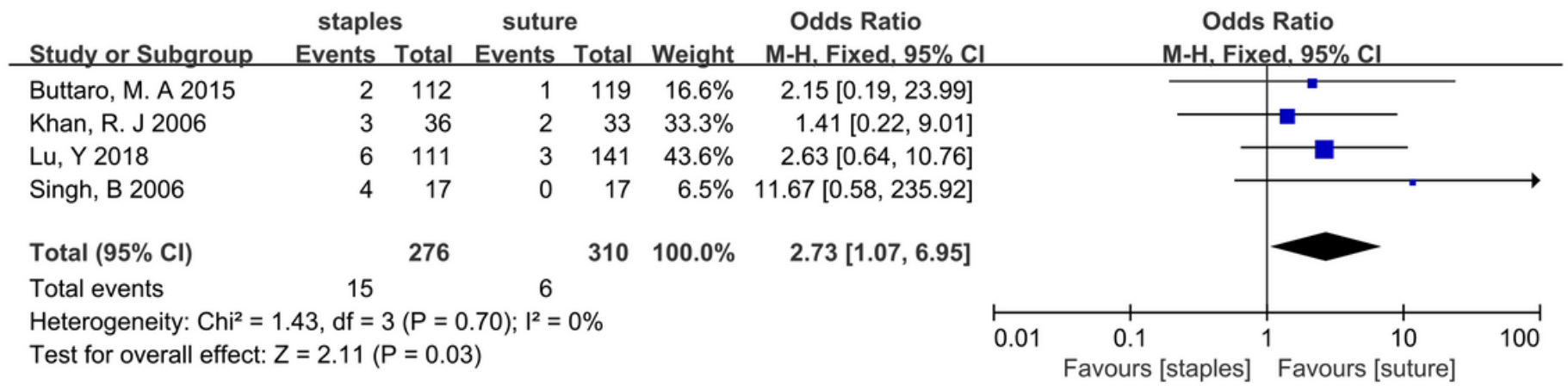

Figure 5

Forest plot for prolongde discharge

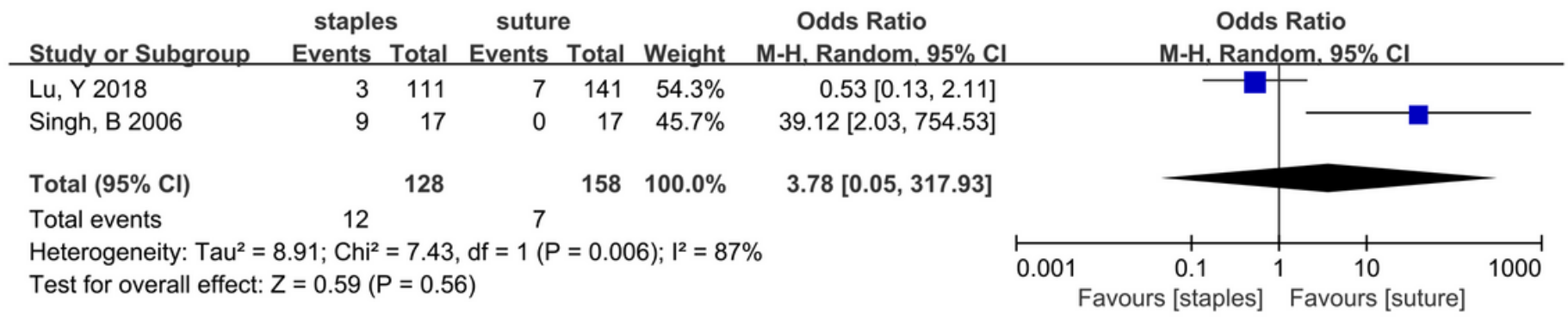

Figure 6

Forest plot for inflammation 
staples Suture Odds Ratio Odds Ratio

Study or Subgroup Events Total Events Total Weight $\mathrm{M}-\mathrm{H}$, Fixed, $95 \% \mathrm{Cl} \quad \mathrm{M}-\mathrm{H}, \mathrm{Fixed}, 95 \% \mathrm{Cl}$

8.1.1 abscess

Khan, R. J 2006

Lu, Y 2018

Subtotal $(95 \% \mathrm{Cl})$

Total events

Heterogeneity: Not applicable

Test for overall effect: $Z=0.74(P=0.46)$

8.1.2 wound dehiscence

Lu, Y 2018

Rui, M 2018

Subtotal $(95 \% \mathrm{Cl})$

Total events
$0 \quad 36$

$0 \quad 111$

147

0
$133 \quad 16.8 \%$

0 141

$174 \quad 16.8 \%$

1
$0.30[0.01,7.54]$

Not estimable $0.30[0.01,7.54]$

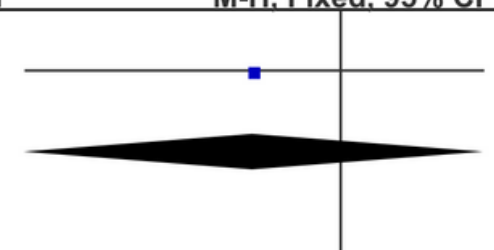

Heterogeneity: Not applicable

Test for overall effect: $Z=0.53(P=0.60)$

8.1.3 allergic reaction

Buttaro, M. A 2015

Khan, R. J 2006

Subtotal $(95 \% \mathrm{Cl})$

Total events
$0 \quad 111$

$0 \quad 83$

194

0
Heterogeneity: $\mathrm{Chi}^{2}=0.03, \mathrm{df}=1(\mathrm{P}=0.86) ; \mathrm{I}^{2}=0 \%$

Test for overall effect: $Z=1.27(P=0.21)$

$\begin{array}{rrrrr}2 & 112 & 5 & 119 & 52.0 \% \\ 0 & 36 & 1 & 33 & 16.8 \% \\ & 148 & & 152 & 68.8 \% \\ 2 & & 6 & & \end{array}$

$0.41[0.08,2.18]$

$0.30[0.01,7.54]$

$0.39[0.09,1.69]$

$0.42[0.02,10.41]$

Not estimable

$0.42[0.02,10.41]$

1
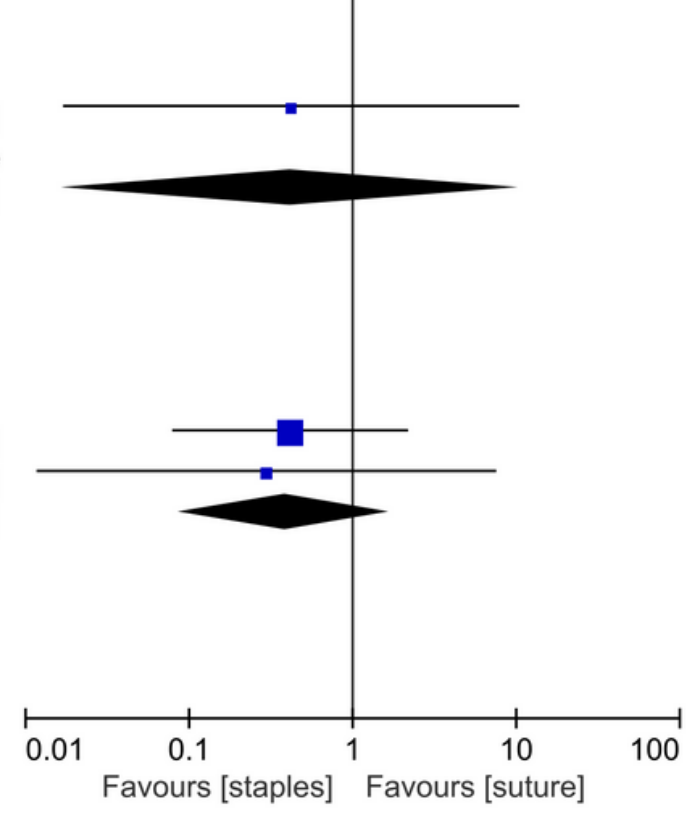

Figure 7

Forest plot for abscess, wound dehiscence, allergic reaction. 